\title{
Adult Grade I Meningioma
}

National Cancer Institute

\section{Source}

National Cancer Institute. Adult Grade I Meningioma. NCI Thesaurus. Code C71299.

A grade I meningioma that occurs during adulthood. 